\title{
INVERSING GLACIER ALBEDO IN HIGH MOUNTAIN ASIA BASED ON SENTINEL-3 SATELLITE DATA
}

\author{
Yixiang $\operatorname{Tian}^{1,2^{*}}$, Zejun $\operatorname{Liu}^{1,2}$ \\ ${ }^{1}$ Center for Spatial Information Science and Sustainable Development and Applications, Tongji University, 1239 Siping Road, \\ Shanghai, China - tianyixiang@tongji.edu.cn zjliu@tongji.edu.cn \\ ${ }^{2}$ College of Surveying and Geo-Informatics, Tongji University, 1239 Siping Road, Shanghai, China
}

Commission TCIII, WG III/9

KEY WORDS: High Mountain Asia, Glacier, Albedo, Sentinel-3, Remote sensing, RGI6.0

\begin{abstract}
:
Surface albedo, defined as the ratio of the upward to downward solar irradiance, is an important climate parameter in the surface energy budget. Among them, glacier albedo is the link between glaciers and the hydration process of climate and cold zones, and it is also an important factor restricting the development of distributed glacier energy-material balance model. Changes in the albedo of ice and snow can alter the energy balance of the entire geo-gas system and can also cause local and even global climate change. Glaciers in High Mountain Asia have experienced heterogeneous rates of loss since the 1970s. The positive feedback effect of ice and snow makes its albedo an important indicator of ice and snow surface mass balance. This study used partly Sentinel-3 level-1b data of High Mountain Asia in 2017, RGI (Randolph Glacier Inventory)6.0 and SPP (Snow Properties Processor) developed by the ESA's team to extract the region's mountain glacier albedo in SNAP (Sentinel Application Platform) environment. At present, the products of the whole year of 2017 have been produced, with a time resolution of one month and a spatial resolution of $300 \mathrm{~m}$.
\end{abstract}

\section{INTRODUCTION}

High Asia, with the Qinghai-Tibet Plateau as the center, is a high mountain plateau in central Asia, which is known as the third largest cryosphere on earth besides the South and North Poles(Donlon et al., 2012). Its high mountains, distributed a large number of modern glaciers, cover an area of $127,000 \mathrm{~km}^{2}$, accounting for about $25 \%$ of the total area of the world's glaciers (excluding the Antarctic and Greenland ice sheets). Figure 1 shows the distribution of mountain glaciers in this region(Box et al., 2012). In this area, glacier melted with the speed about $150 \mathrm{~km}^{3} / \mathrm{y}$, about half of the melted water is fed to inland and arid rivers, and its glacier retreat contributes $20 \%$ to global sea level rise(Immerzeel et al., 2010). Therefore, High Asian glaciers have a significant impact on global climate change, regional water cycle and ecological environment(Dehecq et al., 2019). And it is an important mission for human to monitor some information which can reflect the changes of glacier.

The development of satellite remote sensing technology overcomes the limitation that the surface stations can only observe the data at a single point on the earth surface. Thus, it can make it possible to observe the surface parameters in a large area with high spatial and temporal resolution. Ice and snow albedo is defined as the ratio of upward and downward radiation fluxes of the sun, and it is the important physical parameters influencing wide-spaced sampling system energy balance(Tian et al., 2019). Albedo overcomes the fact that reflectivity can only reflect the energy budget of the ground object in one direction(Brown and Robinson, 2011). And it reflects the absorption of energy from the solar radiation, reflecting energy to the whole hemispheric space, and the ratio of energy can more accurately and comprehensively reflect the energy budget of the surface features(He et al., 2018). When global temperature rises, glacier melted, the exposed earth's surface albedo is lower than those surfaces covered by ice and snow. This phenomenon will not allow more of the solar radiation energy reflected back into the atmosphere, and it can make land surface temperature rise further and cause the glacier to melt deeper. This is the positive feedback effect of ice and snow(Deems et al., 2013). So, ice and snow albedo plays an important role in the mass balance of the glacier surface(Ding et al., 2019). Through remote sensing technology, the albedo information of large area and high time resolution of surface snow and ice can be obtained, and the diurnal, monthly and interannual variation information of albedo can be counted, so as to not only reflect the energy variation of snow and ice to solar radiation, but also explain the variation law of regional snow and ice albedo, and give a scientific explanation for the future snow and ice to indicate the mass loss(Jiao et al., 2019). At present, many remote sensing products for surface albedo inversion based on satellite remote sensing technology have been published in the academic circle, such as MOD10A1(Klein and Stroeve, 2002),Globalalbedo(Calleja et al., 2021), GLASS(Liang, 2001) and so on.

Different remote sensing products retrieve albedo information according to different algorithms. At present, there are four main inversion methods(Kokhanovsky et al., 1998). The first method is to estimate the wide band albedo from the narrow band albedo. In a simple way, we first assume that the earth's surface is a Lambertian body, and obtain the surface reflectance of each spectral segment (narrow band) of the sensor. Then, according to the proportion of each spectral segment in the total solar radiation, we estimate the albedo of the short wave band (wide band) by means of integration(Manninen et al., 2021). The second one is based on the estimation of radiative transfer model. By inputting the physical parameters such as the optical equivalent particle size, shape and absorption coefficient of snow into the radiative transfer equation, the reflection of light with a certain wavelength entering the snow surface can be simulated. By simulating the binomial reflectance distribution function of ice and snow, the albedo can be obtained. MOD10A1(Kokhanovsky, 2002) is

\footnotetext{
* Corresponding author
} 
based on this algorithm. The third method is based on physical inversion estimation. This method can accurately describe the surface reflection in a certain period of time. By obtaining enough surface reflectance data in a certain time range, the unknown parameters in the binomial reflectance model are solved, and then the spectral albedo is obtained by numerical integration of the model in hemispherical space, The wide band albedo is obtained(Jafariserajehlou et al., 2021). The last one is the direct inversion estimation method, which uses a large number of existing high-quality binomial reflectance training data to establish the statistical relationship between the atmospheric top reflectance or surface reflectance and the surface wide band albedo to estimate the surface wide band albedo.

Over the years, relevant scholars have compared and verified the existing remote sensing albedo products in different regions and directly compared them with the measured data on the ground. And the work of evaluating the inversion accuracy of products has been gradually carried out.

He et al (2013) obtained the change of glacial albedo in Greenland from 1981 to 2012 with the GLASS data product, and the inversion results showed that the glacial surface albedo showed a downward trend in the 31 years, and the albedo accelerated to decrease since 2000, especially in the area with an altitude of $1000-1500 \mathrm{~m}$. Tedesco et al (2011) used MODIS data to invert the glacier albedo in summer (May to August) from 2004 to 2010 in Greenland, and the results showed that the albedo in southwest Greenland decreased significantly. Wright et $\mathrm{al}(2014)$ used ASD spectrometer to measure the albedo of ice and snow in Greenland, compared and verified the MODIS products with the measured results. The results showed that the inversion of MODIS products was good and consistent with the measured results on the ground.

In the High Asian mountain glacier region, some scholars have also conducted product quality assessment based on remote sensing products and ground measured data. The results of the study by Qu et al (2014)showed that the albedo of the Zadang Glacier showed an overall downward trend from 2001 to 2010 , and the results were compared with the measured data of mass balance of the Zadang Glacier from 2006 to 2012. The results showed that the decreased albedo increased the melting of the glacier. Ming et al (2012) retrieved the albedo of 11 glaciers on the northern and southern slopes of the Himalayas from 2000 to 2009 , and the results showed that the albedo of most glaciers showed a downward trend during the 10-year period.

However, it has always been one of the research hotspots to develop an albedo inversion algorithm adapted to snow and ice attributes and glacier albedo remote sensing products with higher spatial and temporal resolution.

The ESA's team has proposed a new technique to determine snow optical and microphysical properties using OLCI(Ocean and Land Colour Instrument) on board ESA Sentinel-3 mission(Alexander A. Kokhanovsky and Zege, 2004). This algorithm recognizes the snow and ice on the land surface and extracts the physical characteristics of the snow and ice, including the snow and ice albedo(Essery et al., 2013).

The Randolph Glacier Inventory (RGI) is a global inventory of glacier outlines(Fettweis et al., 2013). It is supplemental to the Global Land Ice Measurements from Space initiative (GLIMS). Production of the RGI was motivated by the Fifth Assessment Report of the Intergovernmental Panel on Climate Change (IPCC AR5)(Holland et al., 2012). In this study, the latest version of
RGI called RGI6.0 released in July 2017 is used to extract the glacier catalogue data of High Asia region, which is used as the benchmark data for mountain glacier albedo extraction.

This research mainly uses Sentinel-3 satellite data, based on the snow processor developed by ESA team, in the SNAP(Sentinel Application Platform) environment to perform the High Asian region mountain glacier 2017 annual short-wave broadband spherical albedo product, the spatial resolution of the product is $300 \mathrm{~m}$, the time resolution is 1 month.

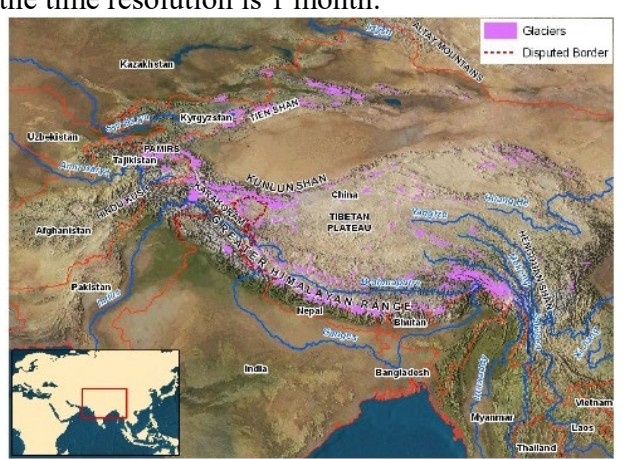

Figure 1. High Asia Mountain ranges, river systems, and glaciers of High Asia.(USAID,2018)

\section{DATA}

Sentinel-3 is a constellation of Earth Observation Satellites developed by the European Space Agency as part of the Copernicus project(Hansen and Nazarenko, 2004). The first Sentinel-3A satellite was launched in 16 February 2016 and Sentinel-3B in 25 April 2018. The two stars share orbits and making the re-entry period less than 2 days.

The basic data selected in this study is the sentinel-3 satellites equipped with OLCI level-1B full resolution product. The resolution of the image is $300 \mathrm{~m}$. The swath of OLCI is $1270 \mathrm{~km}$. The data include 21 OLCI spectral bands in the spectral range $400 \mathrm{~nm}$ to $1020 \mathrm{~nm}$ from the Global Observation (EO) model, and these bands are corrected, geolocation, and spatial resampling of the upper atmospheric radiance values(Knap et al., 1999). The spatial resolution of the image data is $300 \mathrm{~m}$ and we choose the NTC(Non-Time Critical)product because this time mode means they are delivered not later than 1 month after acquisition or from long-term archives. This can ensure that the data used has been fully processed by the ground data center, which greatly improves the data accuracy. One data file includes 21 band files, one quality flags file and other information. The format of band files is NetCDF.

This study used 65 sentienl-3 scenes that were downloaded from the sentinel official website. The download time window is limited in January 1, 2017 to December 31, 2017. Due to the complex climate change on the Qinghai-Tibet Plateau, during May to September 2017, the image quality in the southeastern region of Tibet is generally common, with more cloud cover over the glacier in the image. In the rest period, through visual screening, the Sentinel-3 images with better quality covering the whole region of High Asia can be selected basically. 


\section{METHOD}

\subsection{Algorithm}

The algorithm mainly includes two parts, the first is ice and snow recognition, the second is inversion of snow albedo(Rittger et al., 2013).

The algorithm needs to meet the following three conditions for snow and ice recognition. The first condition is the snow pixel identified in the algorithm must be $100 \%$ snow cover. The second is based on the following formula

$$
\mathrm{NDSI}=\frac{R(865 \mathrm{~nm})-R(1020 \mathrm{~nm})}{R(865 \mathrm{~nm})+R(1020 \mathrm{~nm})}>0.03
$$

Where NDSI is the normalized snow and ice coefficient, $\mathrm{R}(865 \mathrm{~nm})$ is the reflectance of the band and the center wavelength is $865 \mathrm{~nm}$. The last condition is $R(410 \mathrm{~nm})>0.5$.

The algorithm for the inversion of snow and ice albedo by Sentinel-3 is mainly based on the asymptotic radiation transfer model(A. A. Kokhanovsky and Zege, 2004). The formula is as follows

$$
\begin{gathered}
R=R_{0} \exp \left(-x \sqrt{\left(\alpha+f \lambda^{-m}\right) l}\right) \\
r_{p}=\exp \left(-u\left(\mu_{0}\right) \sqrt{\left(\alpha+f \lambda^{-m}\right) l}\right) \\
r_{s}=\exp \left(-\sqrt{\left(\alpha+f \lambda^{-m}\right) l}\right) \\
r\left(\lambda_{1}, \lambda_{2}\right)=\frac{\int_{\lambda_{1}}^{\lambda_{2}} r(\lambda) F(\lambda) d \lambda}{\int_{\lambda_{1}}^{\lambda_{2}} F(\lambda) d \lambda}
\end{gathered}
$$

Where $R$ is reflectance, $R_{0}$ is the reflectance of non-absorbing snow layer, $r_{p}$ is the plane albedo, $r_{s}$ is the sphere albedo, $x$ is a parameter related to solar azimuth and observed azimuth, $\alpha$ is a parameter related to wavelength, $l$ is a parameter related to snow particle size, $f$ and $m$ are parameters related to pollutant concentration(Duguay and Ledrew, 1992), $r\left(\lambda_{1}, \lambda_{2}\right)$ is the broadband albedo(According to the wavelength range in the brackets, it can be divided into visible light, near-infrared, shortwave albedo and so on), $r(\lambda)$ is the spectral albedo of a certain band , $F(\lambda)$ is the solar flux function transmitted through the snow surface with a given solar zenith angle cosine and $u\left(\mu_{0}\right)$ is the function about solar zenith angle(SAUNDERS, 1990).

When wavelength, solar Angle and observation Angle are known, unknown parameters remain in Equation (2), (3), (4) are $R_{0}, l, f, m$. Therefore, the algorithm can solve the remaining unknowns by inputting the reflectivity data of the four bands(Warren, 2019). The four bands suggested by the algorithm are $400 \mathrm{~nm}, 560 \mathrm{~nm}, 865 \mathrm{~nm}$ and $1020 \mathrm{~nm}$, respectively(Picard et al., 2016). After the spectral albedo is obtained, the corresponding broadband albedo can be solved by Equation (5).

At present, ESA has developed a toolkit based on this algorithm. As a plug-in, the toolkit is available for users to download for free on ESA official website. Users can load it into SNAP and retrieve ice snow albedo based on sentinel-3 image through running software.

\subsection{Inversing albedo}

In the data download process of this study, according to the month time window to retrieve the image data, through visual screening, we selected 5-7 scenes images a month whose quality is good with no clouds or less cloud covering the glacier in them, and images monthly High mountain glaciers in Asia can be covered the whole domain, in figure 3 (a) (b) (c) for each month namely images coverage. In this way, the temporal resolution of the High Asian mountain glacier albedo product is 1 month and the spatial resolution is $300 \mathrm{~m}$. After the images are downloaded, They are inputted into SPP, which is a plugin in SNAP, as input data. (d) in Fig. 2 is the visual interface of setting parameters in SNAP in the process of inversion of albedo. Setting parameters as default values, then the inversion of albedo can be carried out. Then, the product coordinate system is set as WGS1984 by using the projection transformation tool in SNAP. Then 5-7 products per-month are raster synthesized in ArcGIS. During the synthesis process, the average pixel value of the overlapping pixels is taken as the final output pixel value. Finally, glacier albedo information is extracted through RGI6.0 mask to generate monthly High Asian mountain glacier albedo products in TIFF file format. Chart (e) is the inversion flow chart given by the government. We only carried out the preliminary production of the product in the designated part of the red arrow, which viewed as the standard flow in this product production. The remaining steps of the process display are subject to further study.
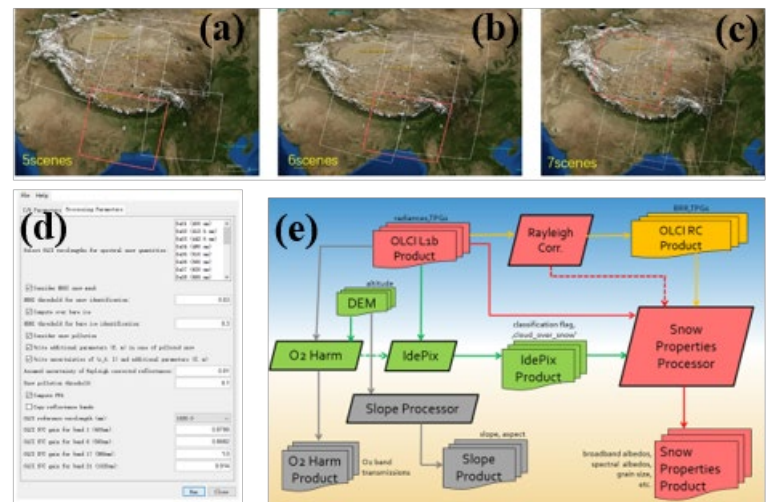

Figure 2. (a)(b)(c) Sentinel-3 images cover the High Asian region.

(d) SPP software interface(ESA,2021.).

(e) Inverse flow chart.( SEOM S3 for Snow Soft User Manual, 2021)

\section{RESULTS}

Based on the above methods and data, we have completed the production of High Asian mountain glacier albedo products for the whole year of 2017 . The time resolution is one month, the spatial resolution is $300 \mathrm{~m}$, and the product data format is TIFF. Figure 3 shows the High Asian mountain glacier albedo product in April 2017 based on Sentinel-3 inversion. Figure 4 shows the extracted Palong 4 Glacier $\left(29.252^{\circ} \mathrm{N} ; 96.932^{\circ} \mathrm{E} ; 4800 \mathrm{~m}\right)$ albedo results on June 2017. Figure 5 shows that the extracted albedo results of $24 \mathrm{~K}$ Glacier $\left(29.766^{\circ} \mathrm{N} ; 95.712^{\circ} \mathrm{E}\right)$ on March 2017. 


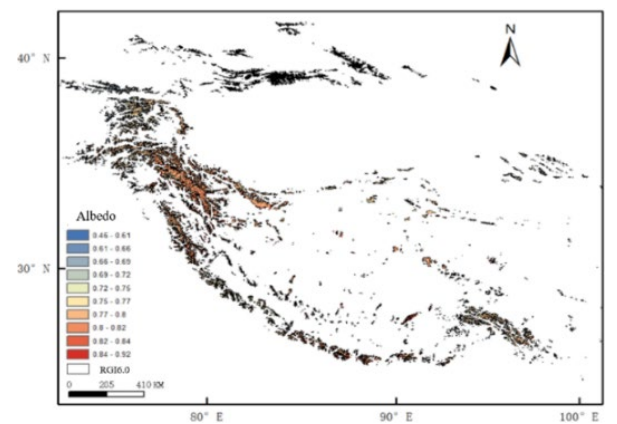

Figure 3. Sentinel-3 inversion of albedo of High mountain glaciers in Asia on April 2017.

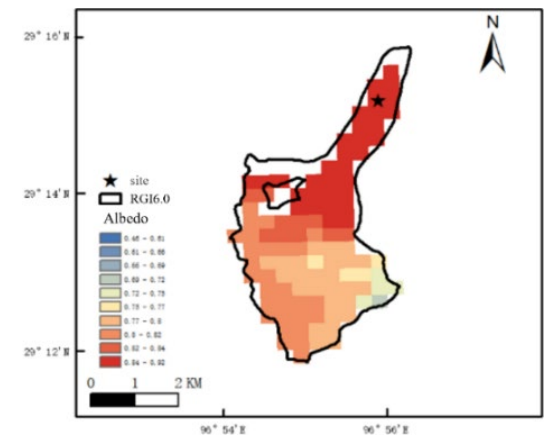

Figure 4. Sentinel-3 inversion of the albedo of Palong Glacier 4 on June 2017.

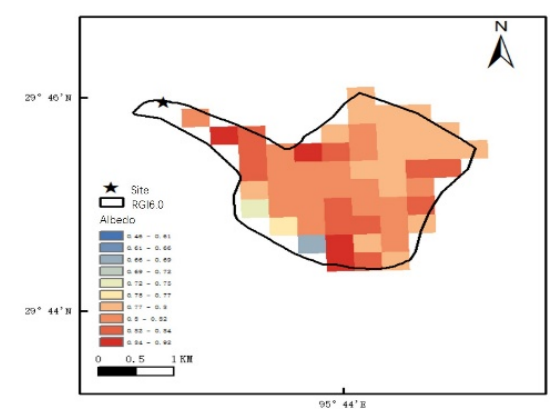

Figure 5. Sentinel-3 inversion of the albedo of $24 \mathrm{~K}$ Glacier on March 2017.

\section{CONCLUSION}

In this research, we used the SPP embedded in SNAP developed by ESA based on the Sentinel-3 image, and extracted inversing results by RGI6.0 data masking. It was produced that the albedo product of mountain glaciers in the High Asian region in 2017. The temporal resolution of the product is 1 month, and the spatial resolution is $300 \mathrm{~m}$.

Through the inversion results of existing tools, it can be known that the algorithm has a good effect on snow and ice recognition, but it depends on the quality of the images. If a large number of clouds appear in the image, the algorithm has a poor effect on cloud and snow recognition. Through tool inversion, the albedo results of High Asian mountain glaciers can be well extracted. For some glaciers, we can extract the albedo easily. It demonstrated that the SPP can provide a good tool reference for remote sensing inversion of albedo of large area mountain glaciers.

In the next step, direct verification of inversion results should be carried out by combining with more land surface meteorological station data and cross-validation with similar products, so as to further evaluate the inversion accuracy of the product and further study its applicability in the inversion of glacier albedo in High Asian mountain regions.

\section{ACKNOWLEDGEMENTS}

This research was supported by the National Key Research and Development Program of China(2017YFA0603103).

\section{REFERENCES}

Box, J.E., Fettweis, X., Stroeve, J.C., Tedesco, M., Hall, D.K., Steffen, K., 2012. Greenland ice sheet albedo feedback: thermodynamics and atmospheric drivers. Cryosphere 6, 821839. https://doi.org/10.5194/tc-6-821-2012

Brown, R.D., Robinson, D.A., 2011. Northern Hemisphere spring snow cover variability and change over 1922-2010 including an assessment of uncertainty. Cryosphere 5, 219-229. https://doi.org/10.5194/tc-5-219-2011

Calleja, J.F., Muniz, R., Fernandez, S., Corbea-Perez, A., Peon, J., Otero, J., Navarro, F., 2021. Snow Albedo Seasonal Decay and Its Relation With Shortwave Radiation, Surface Temperature and Topography Over an Antarctic ICE Cap. IEEE JOURNAL OF SELECTED TOPICS IN APPLIED EARTH OBSERVATIONS AND REMOTE SENSING. https://doi.org/10.1109/JSTARS.20 21.3051731

Deems, J.S., Painter, T.H., Finnegan, D.C., 2013. Lidar measurement of snow depth: a review. Journal of Glaciology 59, 467-479. https://doi.org/10.3189/2013JoG12J154

Dehecq, A., Gourmelen, N., Gardner, A.S., Brun, F., Goldberg, D., Nienow, P.W., Berthier, E., Vincent, C., Wagnon, P., Trouvé, E., 2019. Twenty-first century glacier slowdown driven by mass loss in High Mountain Asia. Nature Geosci 12, 22-27. https://doi.org/10.1038/s41561-018-0271-9

Ding, A., Jiao, Z., Dong, Y., Qu, Y., Zhang, X., Xiong, C., He, D., Yin, S., Cui, L., Chang, Y., 2019. An assessment of the performance of two snow kernels in characterizing snow scattering properties. International Journal of Remote Sensing 40, 6315-6335. https://doi.org/10.1080/01431161.2019.1590878

Donlon, C., Berruti, B., Buongiorno, A., Ferreira, M.-H., Féménias, P., Frerick, J., Goryl, P., Klein, U., Laur, H., Mavrocordatos, C., Nieke, J., Rebhan, H., Seitz, B., Stroede, J., Sciarra, R., 2012. The Global Monitoring for Environment and Security (GMES) Sentinel-3 mission. Remote Sensing of Environment 120, 37-57. https://doi.org/10.1016/j.rse.2011.07.0 24

Duguay, C.R., Ledrew, E.F., 1992. Estimating surface reflectance and albedo over rugged terrain from Landsat-5 Thematic Mapper. Photogrammetric Engineering \& Remote Sensing 58, 551-558. https://doi.org/10.1109/36.142950

Essery, R., Morin, S., Lejeune, Y., Menard, C.B., 2013. A comparison of 1701 snow models using observations from an alpine site. Advances in Water Resources 55, 131-148. https://doi.org/10.1016/j.advwatres.2012.07.013

ESA, 2021. Earth Observation Mode - FR or RR TOA Radiances -Sentinel [WWW Document], n.d. URL https://sentinel.esa.int/w 
eb/sentinel/technical-guides/sentinel-3-olci/level-1/fr-or-rr-toaradiances (20 April 2021)

Fettweis, X., Franco, B., Tedesco, M., van Angelen, J.H., Lenaerts, J.T.M., van den Broeke, M.R., Gallee, H., 2013. Estimating the Greenland ice sheet surface mass balance contribution to future sea level rise using the regional atmospheric climate model MAR. Cryosphere 7, 469-489. https://doi.org/10.5194/tc-7-469-2013

Hansen, J., Nazarenko, L., 2004. Soot climate forcing via snow and ice albedos. Proceedings of the National Academy of Sciences 101, 423-428. https://doi.org/10.1073/pnas.223715710 0

He, C., Liou, K.-N., Takano, Y., Yang, P., Qi, L., Chen, F., 2018. Impact of Grain Shape and Multiple Black Carbon Internal Mixing on Snow Albedo: Parameterization and Radiative Effect Analysis. Journal of Geophysical Research-Atmospheres 123, 1253-1268. https://doi.org/10.1002/2017JD027752

He, T., Liang, S., Yu, Y., Wang, D., Gao, F., Liu, Q., 2013. Greenland surface albedo changes in July 1981-2012 from satellite observations. ENVIRONMENTAL RESEARCH LETTERS. https://doi.org/10.1088/1748-9326/8/4/044043

Holland, M.M., Bailey, D.A., Briegleb, B.P., Light, B., Hunke, E., 2012. Improved Sea Ice Shortwave Radiation Physics in CCSM4: The Impact of Melt Ponds and Aerosols on Arctic Sea Ice. Journal of Climate 25, 1413-1430. https://doi.org/10.1175/J CLI-D-11-00078.1

Immerzeel, W.W., van Beek, L.P.H., Bierkens, M.F.P., 2010. Climate Change Will Affect the Asian Water Towers. Science 328, 1382-1385. https://doi.org/10.1126/science.1183188

Jafariserajehlou, S., Rozanov, V.V., Vountas, M., Gatebe, C.K., Burrows, J.P., 2021. Simulated reflectance above snow constrained by airborne measurements of solar radiation: implications for the snow grain morphology in the Arctic. Atmospheric Measurement Techniques 14, 369-389. https://doi.org/10.5194/amt-14-369-2021

Jiao, Z., Ding, A., Kokhanovsky, A., Schaaf, C., Breon, F.-M., Dong, Y., Wang, Z., Liu, Y., Zhang, X., Yin, S., Cui, L., Mei, L., Chang, Y., 2019. Development of a snow kernel to better model the anisotropic reflectance of pure snow in a kernel-driven BRDF model framework. Remote Sensing of Environment 221, 198209. https://doi.org/10.1016/j.rse.2018.11.001

Klein, A.G., Stroeve, J., 2002. Development and validation of a snow albedo algorithm for the MODIS instrument. Annals of Glaciology 34, 45-52. https://doi.org/10.3189/17275640278181 7662

Knap, W.H., Brock, B.W., Oerlemans, J., Willis, I.C., 1999. Comparison of Landsat TM-derived and ground-based albedos of Haut Glacier d'Arolla, Switzerland. International Journal of Remote Sensing 20, 3293-3310. https://doi.org/10.1080/014311 699211345

Kokhanovsky, A.A., 2002. Statistical properties of a photon gas in random media. Physical Review E 66, 037601. https://doi.org/10.1103/PhysRevE.66.037601

Kokhanovsky, A.A., Nakajima, T., Zege, E.P., 1998. Physically based parameterizations of the short-wave radiative characteristics of weakly absorbing optically thick media: application to liquid-water clouds. Applied Optics 37, 4750 4757. https://doi.org/10.1364/AO.37.004750

Kokhanovsky, Alexander A., Zege, E.P., 2004. Scattering optics of snow. Appl. Opt. 43, 1589-1602. https://doi.org/10.1364/AO .43 .001589

Kokhanovsky, A. A., Zege, E.P., 2004. Scattering optics of snow. Appl Opt 43, 1589-1602. https://doi.org/10.1364/AO.43.001589

Liang, S., 2001. Narrowband to broadband conversions of land surface albedo I: Algorithms. Remote Sensing of Environment 76, 213-238. https://doi.org/10.1016/S0034-4257(00)00205-4

Manninen, T., Anttila, K., Jaaskelainen, E., Riihela, A., Peltoniemi, J., Raisanen, P., Lahtinen, P., Siljamo, N., Tholix, L., Meinander, O., Kontu, A., Suokanerva, H., Pirazzini, R., Suomalainen, J., Hakala, T., Kaasalainen, S., Kaartinen, H., Kukko, A., Hautecoeur, O., Roujean, J.-L., 2021. Effect of smallscale snow surface roughness on snow albedo and reflectance. Cryosphere 15, 793-820. https://doi.org/10.5194/tc-15-7932021

Ming, J., Du, Z., Xiao, C., Xu, X., Zhang, D., 2012. Darkening of the mid-Himalaya glaciers since 2000 and the potential causes. Environmental Research Letters 7, 14021-14033(13). https://oi.org/10.1088/1748-9326/7/1/014021

Picard, G., Libois, Q., Arnaud, L., 2016. Refinement of the ice absorption spectrum in the visible using radiance profile measurements in Antarctic snow. The Cryosphere 10, 2655-2672. https://doi.org/10.5194/tc-10-2655-2016

Qu, B., Ming, J., Kang, S.-C., Zhang, G.-S., Li, Y.-W., Li, C.-D., Zhao, S.-Y., Ji, Z.-M., Cao, J.-J., 2014. The decreasing albedo of the Zhadang glacier on western Nyainqentanglha and the role of light-absorbing impurities. Atmospheric Chemistry and Physics 14, 11117-11128. https://doi.org/10.5194/acp-14-11117-2014

Rittger, K., Painter, T.H., Dozier, J., 2013. Assessment of methods for mapping snow cover from MODIS. Advances in Water Resources 51, 367-380. https://doi.org/10.1016/j.advwatr es.2012.03.002

SEOM S3 for Snow Soft User Manual, 2021. The SNAP S3SNOW Processors - SEOM S3 for Snow / SICE [WWW Document], n.d. URL https://s3tbx-snow.readthedocs.io/en/lates t/s3snow_processing_system.html (20 April 2021).

SAUNDERS, R.W., 1990. The determination of broad band surface albedo from AVHRR visible and near-infrared radiances. International Journal of Remote Sensing 11, 49-67. https://doi.or $\mathrm{g} / 10.1080 / 01431169008955000$

Sentinel Online - ESA - Sentinel [WWW Document], n.d. URL https://sentinel.esa.int/web/sentinel/home (20 April 2021).

Tedesco, M., Fettweis, X., van den Broeke, M.R., van de Wal, R.S.W., Smeets, C.J.P.P., van de Berg, W.J., Serreze, M.C., Box, J.E., 2011. The role of albedo and accumulation in the 2010 melting record in Greenland. Environ. Res. Lett. 6, 014005. https://doi.org/10.1088/1748-9326/6/1/014005

Tian, Y., Qi, H., Li, R., 2019. Greenland Albedo Reanalysis Product and Preliminary Accuracy Assessment, in: IGARSS 2019 - 2019 IEEE International Geoscience and Remote Sensing 
Symposium. Presented at the IGARSS 2019 - 2019 IEEE International Geoscience and Remote Sensing Symposium, IEEE, Yokohama, Japan, pp. 4068-4071. https://doi.org/10.1109/IGAR SS.2019.8898778

USAID,2018,Project Summary | Research Project: Contribution to High Asia Runoff from Ice \& Snow [WWW Document], n.d. URL https://nsidc.org/charis/project-summary/ (20 April 2021).

Warren, S.G., 2019. Optical properties of ice and snow. Philosophical Transactions of The Royal Society A Mathematical Physical and Engineering Sciences 377. https://doi .org/10.1098/rsta.2018.0161

Wright, P., Bergin, M., Dibb, J., Lefer, B., Domine, F., Carman, T., Carmagnola, C., Dumont, M., Courville, Z., Schaaf, C., Wang, Z., 2014. Comparing MODIS daily snow albedo to spectral albedo field measurements in Central Greenland. Remote Sensing of Environment 140, 118-129. https://doi.org/10.1016/j. rse.2013.08.044 